Acta Poetica $35 \cdot 2$

JULIO-DICIEMBRE

$2014(149-165)$

\title{
La mística al revés en el cuento "Rito" de Juan García Ponce
}

\begin{abstract}
Alfredo Rosas Martínez
La mística no siempre ha transitado por el mismo camino ni en el mismo sentido. En algunas obras de literatura se presenta como una mística al revés. En el cuento "Rito", de Juan García Ponce, se lleva a cabo un proceso místico transitando los caminos del mal. A partir de la desnudez del cuerpo de una mujer joven y hermosa, del erotismo y del acto sexual se pretende que el Espíritu de la Divinidad se manifieste. En este cuento está presente la transgresión y la perversión de las normas sociales de comportamiento dentro del matrimonio. Los personajes del cuento, Liliana y Arturo, son esposos. Sin embargo, les gusta practicar un rito en el cual se invita a cenar a un individuo desconocido. De lo que se trata es de poner en práctica "las leyes de la hospitalidad" que el escritor francés Pierre Klossowski propone en sus novelas Roberte, esta noche y en La revocación del Edicto de Nantes. En el nivel profano, el esposo, como Señor de la casa, debe acceder al nivel místico de Anfitrión; a su vez, la Señora de la casa, como esposa, debe acceder al nivel místico de Anfitriona. Para ello, el esposo debe ofrecer a su esposa al invitado, como Tercero desconocido. El esposo, como Anfitrión, contempla el acto sexual de su esposa con el invitado: ella es la Anfitriona; y el Tercero desconocido funciona como el elemento angelical que comunica lo profano con lo sagrado. En el acto sexual y en la desnudez del cuerpo de la hermosa mujer se manifiesta el Espíritu de la Divinidad.
\end{abstract}

PAlabRas ClaVe: García Ponce, "Rito”, mística al revés, erotismo, perversión, leyes de la hospitalidad.

Mysticism has not always gone through the same road nor in the same sense. In some works of literature it is presented as an inverted mysticism. In the story "Rito", by Juan García Ponce, a mystical process is performed traversing the ways of evil. Commencing with the nakedness of a Young beautiful woman's body, the eroticism and the sexual act, it is intendend that the Spirit of Divin- 
ity manifests itself. In this story the transgression and perversion of the social norms of behavior within marriage is present. The characters in the story, Liliana and Arturo are spouses. However, they like to practice a ritual in which they invite to dinner an unknown individual. The purpose is to put into practice the "laws of hospitality" that the French writer Pierre Klossowski proposed in his novels Roberte tonight and Revocation of the Edict of Nantes. In the secular level, the husband, as master of the house, must access the mystical level of Host; in turn, the Mistress of the house, as wife, must access the mystical level of Hostess. Thus, the husband must offer his wife to the guest, as the unknown Third. The husband, as Host, contemplates his wife's sexual act with the guest: she is the hostess; and the unknown Third functions as the angelic element that connects the profane to the sacred. In the sexual act and in the nakedness of the beautiful woman's body is manifest the Spirit of Divinity.

KEYWORDS: García Ponce, "Rito", mystical backwards, eroticism, perversion, laws of hospitality.

Fecha de recepción: 6 de junio de 2013

Fecha de aceptación: 14 de marzo de 2014 


\section{Alfredo Rosas Martínez \\ Universidad Autónoma del Estado de México \\ Facultad de Humanidades}

\section{La mística al revés en el cuento "Rito" de Juan García Ponce}

La mística, como la experiencia de lo Divino, con sus tres fases (purificativa, iluminativa y unitiva), no siempre ha transitado por un solo camino y en una sola dirección. También hay una vía negativa (o al revés) del proceso místico que en ocasiones se revela en el ámbito del arte. Algunos artistas muestran preferencia por senderos que no es conveniente frecuentar, ya que son contrarios a la cultura oficial y se mantienen fuera del orden moral y social establecidos (García Ponce, "Thomas Mann", 247); prefieren seguir esa perspectiva del mal como una forma heterodoxa de acceder a lo que ellos consideran la luz de lo Divino: "A partir de una necesidad interior, el artista da testimonio de una vida diferente a la vida inmediata, probando una realidad más allá de toda moral" (García Ponce, Teología, 17).

Los artistas que han frecuentado dicha vía negativa han llegado a constituir una tradición importante. Menciono algunos de ellos. A partir de su actitud atea, de su desprecio por Dios y de su obsesión por rebasar los límites, el Marqués de Sade aspira, transitando la senda del mal, a lo Único y a lo Soberano, a lo divino y a lo eterno. Como afirma Maurice Blanchot:

El hombre de Sade obtiene su existencia de la muerte que da y a veces, deseando una eternidad de vida, sueña con una muerte que pueda dar 
eternamente, de tal manera que el verdugo y la víctima, colocados eternamente, el uno enfrente de la otra, se vean igualmente provistos del mismo poder, del mismo atributo divino de la eternidad (Lautréamont, 38).

En el ámbito de la pintura, Balthus ha realizado una obra en íntima relación con la vertiente libertina del pensamiento gnóstico (cfr. García Ponce, Una lectura). Georges Bataille ocupa un lugar destacado en esta tradición. Con sus aportaciones sobre el erotismo, las relaciones entre la literatura y el mal y, sobre todo, con sus propias obras literarias (novelas como Historia del ojo, y relatos como "Mi madre"), se ha ganado a pulso el título de "místico al revés". Al explicar las claves principales de su novela, Bajo el volcán, Malcolm Lowry mencionó la importancia de la Cábala. En lugar de ascender por las esferas del árbol sefirótico, el personaje principal inicia un camino "al revés", un descenso al abismo del mal. Además, mencionó la relación íntima que puede haber entre la actitud mística y una de las prácticas del mal como es el delirio producido por el exceso de alcohol: "La agonía del ebrio encuentra su más exacta analogía poética en la agonía del místico que ha abusado de sus poderes" (Lowry, El volcán, 37). Más recientemente, Pierre Klossowski ha usado y seguido de cerca, basándose en el lenguaje de la teología, el proceso religioso y místico que experimentan sus personajes para, por medio de la perversión de las costumbres, transgredir el principio teológico de la identidad en Roberte, esta noche y en La revocación del Edicto de Nantes. Al hablar de esta tradición, en la cual se mezclan la perversión y el libertinaje, Juan García Ponce afirma que, entre otras cosas, el libertinaje para los artistas adeptos es "una práctica gozosa [...], mediante la cual se define su manera de ser y de pensar y es una fuente de riqueza para la creación. Hay que guardar ese derecho" ("Algunos apuntes", 7).

En el ámbito de la literatura mexicana, Juan García Ponce ocupa un lugar privilegiado en dicha tradición. En su obra son importantes el sexo, el erotismo, la perversión y la perversidad como elementos de una teología del mal y de una mística al revés. Su obra abarca, principalmente, la novela, el cuento, el ensayo y la traducción. La novela Inmaculada o los placeres de la inocencia es una obra de educación o de 
formación (iba yo a decir: "de deformación") de una mujer joven e inocente en el ámbito del mal. Después de transitar intensamente por los caminos de la perversión, al final de la obra es cuando realmente puede ser considerada "inocente" y se ha ganado el nombre de "Inmaculada". En relación con su novela De anima, la crítica ha destacado la relación entre la mística y el erotismo. A propósito de esto, se ha señalado que desde la antigüedad el misticismo ha estado unido al erotismo, y que:

La unión del alma con Dios se ha expresado a través de la metáfora de dos amantes, de dos seres que, por amarse, no están ligados por medio de vínculos matrimoniales legales. Este tema se hace evidente en la novela de García Ponce, donde el personaje femenino - Paloma - llega a reconocer que la relación con su amante ha sido "ese raro encuentro de nosotros mismos fuera de nosotros mismos", es decir, el rechazo de la posesión en busca de una comunión (Rosado, "Erotismo", 113).

En el cuento "El gato", la dualidad constituida por la desnudez y el erotismo de una joven pareja de amantes se complementa con la figura de un gato que los observa, el cual asume el papel del tercero como voyeur. En el ámbito del ensayo, sus intereses van por el mismo camino. A García Ponce le debemos dos obras fundamentales: la interesante y original interpretación de algunos cuadros de Balthus desde la perspectiva del pensamiento libertino de los gnósticos (Una lectura pseudognóstica de Balthus) y la detallada interpretación de la obra de Pierre Klossowski, en la cual destaca la teología, la pornografía, la perversión, la perversidad en relación con la literatura y el mito (García Ponce, Teología y pornografía). También son importantes sus ensayos en los que señala la relación de la mística con el mal. A propósito de Robert Musil, el escritor mexicano advierte, en El hombre sin atributos, que Ulrich y Agatha, al encontrarse, se hallaban en un camino que tenía mucho en común con las formas adoptadas por aquellos que están poseídos por Dios; no obstante, recorrían ese camino sin creer en un dios o en el alma; lo transitaban como habitantes de este mundo: "Sin embargo, sin llegar nunca a plantearse ni siquiera como posibilidad la existencia de Dios, el camino que recorren se adentra cada vez más por una vía mística, que lleva a Musil incluso a pensar en la creación de una mística atea" (García 
Ponce, La errancia, 37). Asimismo, son importantes sus ensayos sobre Bataille, Thomas Mann y Marcel Proust (Apariciones). En cuanto a su labor como traductor de obras pertenecientes a la tradición del mal en la literatura, ha traducido las novelas de Pierre Klossowski, Roberte esta noche, y La revocación del Edicto de Nantes.

La influencia de Klossowski en algunas obras de García Ponce es determinante. Entre una postura atea y otra religiosa basada en la fe, García Ponce pareciera proponer, por influencia del novelista francés mencionado, una tercera posibilidad: la del arte. Desde este punto de vista, la necesidad de lo divino exige un desplazamiento de carácter sexual. Lo que el artista dice del Reino de los Cielos, como si fuera un falso profeta, es una contra-manera que debe despertar los apetitos más carnales de sus lectores y contrariar los caminos imprevisibles del Señor. Su única meta consiste en mostrar el puro despliegue de la vida (la fascinación) que encuentra su sentido al realizarse como obra de arte (García Ponce, Teología, 20 y ss.). Para ejercer este oficio perverso en su cuento "Rito", García Ponce elige la institución sagrada del matrimonio. Los recursos principales de que se vale para pervertir dicha institución social son la ironía y la parodia en relación con el proceso místico.

La parodia da cuenta del proceso místico al revés. En la mística ortodoxa, la fase Purificativa se caracteriza por la intención de despertar a una nueva conciencia de la realidad divina. Como dice san Juan de la Cruz, el alma se vuelve hacia Dios "En una noche oscura, / con ansias, en amores inflamada" (Subida, I, en Obras completas, 258), resuelta a salir de la casa de los apetitos y de las imperfecciones. Esta actitud implica una verdadera conversión, de la cual brota, al mismo tiempo, la conciencia de la propia impureza, el deseo imperativo de unión con Dios, y una determinación radical de eliminar los obstáculos que impidan la unión con la divinidad. Un ejemplo es el vehemente deseo de perfección de santa Teresa ante la vista de una imagen de Cristo llagado (Libro de la Vida, en Obras completas, 80). En el periodo purificativo, la Mortificación tiene como meta combatir y destruir los apetitos que disipan las energías del alma. Los apetitos consisten en el deseo desordenado de la voluntad y de los sentidos hacia las cosas tanto materiales como espirituales. La noche para el alma es una desnudez de sí misma: "porque no 
tratamos aquí del carecer de las cosas - porque eso no desnuda el alma si tiene apetito de ellas-, sino de la desnudez del gusto y apetito de ellas, que es lo que deja al alma libre y vacía de ellas, aunque las tenga" (san Juan de la Cruz, Subida, I, en Obras completas, 262). El secreto de la Unión con Dios supone la mirada de unos ojos limpios de deseo.

En el cuento "Rito" de García Ponce encontramos prácticamente lo mismo; pero al revés. El secreto de la Unión espera la mirada de unos ojos llenos de malos deseos. En lugar de luchar contra las tentaciones del cuerpo, es de ellas precisamente de donde parten los jóvenes esposos, Liliana y Arturo. El rito les fue revelado, deslumbrándolos y desconcertándolos, pero su revelación no fue súbita sino progresiva. Liliana y Arturo se conocieron en una fiesta. Ella había terminado recientemente su carrera en una universidad católica. Convencida de su incapacidad para seguir la vida religiosa, sólo daba clases en su antiguo colegio. Arturo, aunque menos ligado a la religión, cumplía con las exigencias de una vida normal. Se hicieron novios y se casaron con el consentimiento de sus respectivas familias. Poco a poco "fueron deslizándose por una pendiente cuyo conocimiento habría horrorizado a sus respectivas familias, a muchos de sus amigos y, en general, a todos los que olvidan que los caminos del Señor son inescrutables" (265). El rito consistía en que, cada determinado tiempo, elegían a un individuo para invitarlo a cenar. En esas ocasiones, Liliana y Arturo prescindían de los servicios de la servidumbre para quedarse solos con el invitado. El arreglo personal de Liliana era sensual y provocativo; también lo era su comportamiento conforme cenaban y tomaban vino. La intención era provocar y seducir al invitado. Después de la cena, Liliana invitaba a bailar al invitado. Mientras bailaban, ella lo incitaba y lo provocaba. Finalmente, terminaban por hacer el amor. Mientras tanto, y frente a ellos, Arturo contemplaba la entrega y el abandono de su esposa viendo cómo un desconocido la poseía. En esta experiencia inaudita, Liliana se transformaba; dejaba de ser ella misma para ser otra totalmente diferente. Al final, ella recobraba su actitud cotidiana y, con ingenuidad e ironía, pronunciaba un ligero reproche a su esposo por imponerle la entrega a un desconocido: "Aunque si alguien más que ellos pudiera escucharlas sus palabras serían escandalosas, tal vez atroces, ése es el mismo tono con el que un inalcanzable momento atrás [antes de iniciar el rito] y sin 
embargo en un continuo presente, ha dicho con voz cristalina y un acento intachable I adore myself: — iQué humillación! — comenta— ¡ Todo el mundo que quiere me coge!" (288).

El gozo que se propone en el cuento de García Ponce es el gozo del cuerpo y de los sentidos. En lugar de apartarse de los apetitos, los esposos se apartaron de los familiares y amigos más cercanos; y para llevar a cabo el ritual místico, prefirieron contar con invitados desconocidos. Como mujer soltera, Liliana era discreta, tímida, pura e inocente; ahora, como mujer casada, y sin perder dichos atributos, con obediencia y humildad, "con ansias de amores inflamada", se dispone, con la debida aprobación de su esposo y en presencia de él, a ofrecerse sexualmente como una puta a un invitado desconocido en un ritual místico y amoroso.

La fase Iluminativa del proceso místico ortodoxo se caracteriza principalmente por una luz inmutable infundida en el alma: "blancura suave y el resplandor infuso" (santa Teresa, Libro de la vida, en Obras completas, 204). San Juan de la cruz compara el alma con una vidriera; y a Dios, con un rayo de sol: el alma "queda esclarecida y transformada en Dios y le comunica Dios su ser sobrenatural de tal manera, que parece el mismo Dios y tiene lo que tiene el mismo Dios" (Subida II, en Obras completas, 304).

En el cuento de García Ponce, Liliana parodia lo divino para propiciar la iluminación. Los movimientos de sus brazos simulan el recogimiento con la sensación de llevar en su interior a la Divinidad después de recibir la comunión. En su entrega total a un desconocido, la divinidad ha de manifestarse en la iluminación que surge de su cuerpo desnudo, hermoso y sensual. Maliciosa y sin renunciar a su inocencia, Liliana conoce la importancia de la vía contemplativa, a la que ella permite existir, "y se ofrece en espectáculo desde un generoso desprendimiento $\mathrm{y}$ una religiosa seguridad en los que, a través de su joven figura, se hace manifiesta la unión entre la carne y el espíritu mediante la que, tal vez, finalmente deberá mostrarse el espíritu a costa de la carne, sirviéndose de ella como su único posible vehículo" (264).

La fase Unitiva del proceso místico ortodoxo se caracteriza por la unión transformante, o matrimonio espiritual; hay un sentimiento cierto e inefable de la presencia de Dios en el alma. Lo distinto se funde. El matrimonio espiritual que se consuma entre Dios y el alma está cons- 
tituido por dos naturalezas en un solo espíritu y en un solo amor: el matrimonio espiritual "es una transformación total en el amado, en que se entregan ambas las partes por total posesión de la una a la otra, con cierta ansia de unión de amor, en que está el alma hecha divina y Dios por participación cuanto se puede en esta vida" (san Juan de la Cruz, Cántico 22, en Obras completas, 827). En los efectos de este matrimonio místico predomina la inocencia y la ausencia del mal.

En el cuento de García Ponce: "Una escena vulgar es el medio para provocar la aparición de lo sagrado. Incomprensible y humillante" (281282). Liliana, la respetable esposa burguesa entregándose a un desconocido, es "una procaz revelación desnuda que no rompe el recato del rostro, la serena severidad de sus facciones y pone en la irresponsabilidad de su figura, afirmada en su descaro y su abierto ofrecimiento, un sello contradictorio e indescifrable" (278). Ella nunca es más pura, virginal e inocente que cuando accede a la plenitud del orgasmo con un extraño y se comporta como una prostituta: "La natural fuerza de la sensualidad se pone al servicio de la perversión que la deforma y negando toda naturalidad entra al campo del espíritu cuando lo que se muestra es el poder de seducción de la carne" (278).

La unión mística es deslumbrante y, al mismo tiempo, es una oscuridad total; también es inefable: "Lo que ocurre a la vista de Arturo no puede describirse, está más allá de las posibilidades del lenguaje común porque sólo es el producto del mudo lenguaje de los cuerpos donde se realiza lo que no puede sustituirse por palabras cuyo significado esté fijo" (283). Lo inefable y lo inexplicable de la aparición de la divinidad están basados en la pura contradicción. El amor pertenece a los esposos, pero a través de la fascinación y el deseo de los otros: en este caso, de un tercero que es el invitado desconocido. Liliana y Arturo sólo encuentran su auténtica posibilidad de unión al negar los principios que los definen como pareja: nunca es más suya que cuando la siente perdida; nunca le es más fiel que cuando le es completamente infiel; nunca es su puro objeto del deseo mas que cuando se convierte en el objeto del deseo de un tercero; nunca participa más del rito que cuando en pleno acto sexual y orgásmico "los gestos de ambos [de ella y del tercero] hablan de una intimidad interior de la que él [el esposo] está excluido" (284). 
El ritual místico llevado a cabo "al revés" en la institución sagrada del matrimonio, sin embargo, está signado por la ironía. La ironía se relaciona con tres de los cuatro epígrafes que acompañan al cuento, pues están en íntima relación con la Divinidad máxima de la sagrada Biblia: "Se han corrompido y se han hecho abominables por sus pasiones" (Sal. 52: 2); "Todos mis deseos se hallan expuestos a vuestros ojos" (Sal. 13: 2); "Dios ama a los que dan" (II. Cor. 9: 7). La ironía se intensifica si tomamos en cuenta el pensamiento herético que considera que el dios de la Biblia sólo es un demiurgo menor.

En efecto, el cuento de García Ponce está en íntima relación con el pensamiento gnóstico. El gnosticismo considera que el mundo es una deficiente y malvada creación de un demiurgo menor que pretendió atribuirse poderes que no le correspondían. Para experimentar la gnosis que conduce a una vida espiritual superior, el gnosticismo posee dos posturas: una asceta, basada en las acciones buenas; otra, libertina que privilegia los vicios, el erotismo y el sexo. Los seguidores del "libertinaje gnóstico" consideran que el oro arrojado en el barro no pierde su belleza: "Por esto, los más perfectos entre ellos practican sin rebozo todas las acciones prohibidas [...] Algunos, entregados a fondo a los placeres de la carne, dicen que dan lo carnal a lo carnal y lo espiritual a lo espiritual" (Irineo ápud Jonas, La religión gnóstica, 290).

La postura libertina está representada principalmente por Carpócrates, quien propone el culto al orgasmo como un liberador de la "luz celeste". Por medio del pecado se paga el precio de la libertad última. Esta idea "constituye el reforzamiento espiritual más poderoso de la tendencia libertina inherente a la rebelión gnóstica como tal y se convierte en precepto positivo del inmoralismo" (Jonas, La religión gnóstica, 293). La aparente inocencia y pureza del cuerpo no es más que un disfraz detrás del cual se oculta la realidad del mal. Esa inocencia siempre es perversa. El cuerpo es culpable. Y, sin embargo, es una vía mística para acceder a lo superior. Al ofrecer los cuerpos a la contemplación, como la vida, el arte inicia esa cadena que sólo puede terminar en el orgasmo mediante el que Carpócrates buscaba liberar la "luz celeste" (García Ponce, Una lectura pseudognóstica, 26 y ss.).

El cuarto epígrafe del cuento de García Ponce está tomado de la novela La revocación del Edicto de Nantes, de Pierre Klossowski: "La 
necesidad de semejantes leyes no se comprende bien y la triste referencia al voyeur no muestra para nada sus misteriosos recursos". ¿A qué leyes se refiere? A las leyes de la hospitalidad, las cuales permiten que la naturaleza humana se eleve a la naturaleza divina por medio de una mística al revés transitando los senderos del mal (cfr. Klossowski, Roberte, 16 y ss.).

Estas leyes de la hospitalidad constituyen un alarde no de perversión, sino de perversidad. El esposo, el respetable señor de la casa, "El señor de estos lares", espera con ansiedad al extranjero (el invitado desconocido) como si fuera su libertador. El señor "estará de antemano agradecido a cualquiera que, en vez de considerar la hospitalidad como un accidente en el alma de aquel y de aquella que la ofrecen, la tomará como la esencia misma del anfitrión y la anfitriona, y el extranjero mismo vendrá como tercero a compartir esa esencia a título de invitado" (17). La hospitalidad bien ejercida (el ofrecimiento de su esposa) le permitirá pasar de simple señor de la casa a ser un verdadero anfitrión. Entre el señor de la casa y el invitado habrá una relación esencial, sustancial, como si se tratara de una relación del anfitrión consigo mismo. El invitado actualiza una posibilidad del anfitrión; y éste actualiza una posibilidad del invitado.

De lo que se trata es de trascender la identidad personal de la esposa. En el cuento de García Ponce, en efecto, el invitado desconocido, para su sorpresa y placer, recibirá como donación a la respetable, joven, hermosa y sensual esposa del señor de la casa. Una de las funciones del invitado consistirá, por medio del acto erótico y sexual, en destruir la identidad de la señora de la casa, a fin de lograr "otra" Liliana que ella misma desconoce, y que revele su esencia verdadera como anfitriona. El objeto de culto será la manifestación de "la otra Liliana" en pleno éxtasis sexual. La literatura se sirve del lenguaje de la teología para transgredir el principio teológico de identidad, el cual indica que la incomunicabilidad propia a cada naturaleza humana impide que participe de otra identidad al mismo tiempo: "el ser de un individuo no

${ }^{1}$ Esta traducción de García Ponce pertenece a la edición de Editorial Era, 1975. En la edición de Tusquets (1998), el mismo García Ponce modifica la traducción: "Ya lo he dicho: no se comprende bien la necesidad de semejantes leyes, y la triste referencia al voyeur no explica en absoluto sus misteriosos mecanismos" (39). 
podría atribuirse a varios individuos, y es lo que constituye de hecho a la persona idéntica a sí misma" (García Ponce, La errancia, 42). Sin embargo, por medio del lenguaje de la literatura, basado en el lenguaje teológico, en ciertos casos extremos, como la posesión o el éxtasis, es posible la asociación a otra naturaleza: el acto sexual de Liliana con el invitado desconocido que ha de revelar a "la otra Liliana" como manifestación del Espíritu por medio de la carne. Desde esta perspectiva, se puede decir que en la literatura, a partir de la ironía y la parodia del lenguaje teológico, "el proceso se hace posible mediante la unión hipostática, la que permite que un cuerpo tenga una doble naturaleza, tal como ocurre en el misterio de la Encarnación" (42).

Otra función del invitado consistirá en poner a prueba la curiosidad del anfitrión mediante los celos y la suspicacia propios del señor de la casa pero indignos de un anfitrión. A su vez, el anfitrión debe poner a prueba la discreción del invitado al ofrecerle sin condición alguna el cuerpo espléndido de su joven y bella esposa.

Los conceptos de "el señor de estos lares" y "la señora de estos lares" pertenecen al ámbito de la existencia de la naturaleza humana, inmediata. Las nociones de anfitrión y anfitriona pertenecen al ámbito místico y perverso de la naturaleza divina. El propósito final de todo esto consiste en proyectar lo esencial divino, la proyección del espíritu, en la existencia, en la vida, como un espectáculo único e irrepetible. La revelación de la esencia de la señora de la casa como anfitriona estará basada en la contradicción. Como su belleza inocente y pura, su apariencia recatada de señora decente y fiel son impedimentos para acceder a dicha esencia, será necesario que en la entrega de su cuerpo al invitado desconocido revele su esencia basada en la traición y en la infidelidad. El señor de la casa la quiere poseer infiel por medio del invitado: "La noción de señora de estos lares se toma bajo la razón de existencia; ella no es una anfitriona sino bajo la razón de la esencia: esa esencia está por lo tanto limitada por su actualización en la existencia en cuanto señora de estos lares. Y la traición no tiene aquí otra función que romper esa limitación" (Klossowski, Roberte, 19).

El invitado, el tercero desconocido que ha de recibir la donación, también debe transformarse. La religiosidad del anfitrión lo convierte en un ángel. El ángel, como símbolo que comunica lo inferior con lo 
superior, tiene la función de revelar la esencia de anfitriona de la señora de la casa que le ofrecen; asimismo, debe precipitar dicha esencia en la existencia como espectáculo, en este caso de carácter sexual, erótico y místico. En el momento en que el ángel, por medio de la seducción y la posesión sexual, logra poner fuera de sí a la señora de la casa revelando su esencia de anfitriona, el señor de la casa se funde con el invitado revelando su esencia de anfitrión que ha cumplido cabalmente con las leyes de la hospitalidad. En "Rito", Liliana tiene que ser de todos

porque no es de nadie y no siendo de nadie es como Arturo la siente suya [...] [y al estar Liliana en la cama con el Tercero, ambos] forman el único posible centro de la sala y su arbitraria presencia en ella la llena de sentido, como si toda realidad tuviera que violentarse hasta obligarla a mostrar su lado contrario para poder alcanzar su verdadero carácter (285).

El cumplimiento de las leyes de la hospitalidad revela el paso de la perversión a la perversidad. La perversión consiste en tomar como punto de referencia una acción buena o positiva para pervertirla desde la perspectiva del mal transgrediendo el orden moral y social establecido. En el cuento de García Ponce se da la perversión en varios niveles. Uno de ellos se refiere a las costumbres en relación con el sagrado matrimonio. La ejemplar pareja, después de haberse jurado fidelidad para toda la vida, pasó a ejercer el ritual en el que el esposo "presta" a su esposa a un desconocido para una experiencia sexual. Durante la seducción y la entrega, Liliana muestra orgullosamente su anillo de matrimonio propio de una señora casada y respetable. No obstante, en el rito, la señora de la casa la hace de puta mientras su marido se complace contemplando la escena. Otro nivel de perversión tiene que ver con el lenguaje teológico y místico. Al iniciar el rito, la actitud de Liliana permite la existencia de "la vía contemplativa". Con una religiosa seguridad, a través de su joven figura se manifiesta la unión de la carne y el espíritu para que, finalmente, este último se manifieste porque así lo quiere la "Suprema Voluntad". Asimismo, en el acto de la seducción y de la entrega al tercero desconocido, Liliana se muestra inocente y sensual al colocar sus brazos a ambos lados de su cabeza "como tantas veces se juntaron sobre su pecho en un gesto de recogimiento con la sensación de llevar en su 
interior a la Divinidad después de recibir la comunión" (265). También aparece la perversión de la contemplación artística: "Casi frente a ella, Arturo la contempla desde su sillón, inmediata y al mismo tiempo intocable, como lo es todo cuadro, admirado por lo que el cuadro muestra en esta ocasión y a la expectativa" (266). Todo ello pertenece al nivel de la existencia o de la naturaleza humana.

La perversidad siempre va más allá de la realidad inmediata. Entendida como el impulso radical, primitivo y elemental de hacer el mal por el mal mismo como si fuera una instigación directa del demonio (cfr. Poe, "El demonio", 192 y ss), la perversidad trastorna las esencias de la naturaleza humana y afecta hasta lo divino. En "Rito", se realiza un acto de perversidad en relación con el principio teológico de la identidad de los seres ya mencionado antes pero que es necesario repetir: "El principio según el cual el ser de un individuo no podría atribuirse a varios individuos, y es lo que constituye de hecho a la persona idéntica a sí misma" (Klossowski, Roberte, 44). Gracias a la perversidad ejercida en este principio teológico, la identidad de los personajes es puesta en tela de juicio. Por medio de la posesión o el éxtasis erótico y sexual con un desconocido, Liliana logra salirse de sí misma para dar lugar a otra Liliana insospechada. No es casual que lo que García Ponce dice de un personaje femenino de Pierre Klossowski sea aplicable a Liliana: "las flexiones de su cuerpo reflejarán el lenguaje de los puros espíritus y cuerpo y espíritu encontrarán su verdad en la representación, el espectáculo, donde, representándose, la vida se encuentra a sí misma y se ofrece como mero espectáculo, como creación del espíritu" (Teología, 56). El Tercero desconocido también se transforma; y lo mismo sucede con Arturo, el esposo de Liliana. En este caso, los personajes se transforman en algo que aspira a elevarse a la naturaleza divina en un acto de transubstanciación. Así como en la mística ortodoxa una de las imágenes propias de la fase unitiva es la revelación de la Santísima Trinidad, imagen de la unión de lo diverso en lo UNO (santa Teresa, Obras completas, VII, 1, 712), en el cuento de García Ponce el señor de la casa como anfitrión es el Padre; el invitado como ángel y receptor de la donación, es el Hijo; y la señora de la casa como anfitriona es, a partir de su desnudez y de su entrega infiel y traicionera, la imagen del espacio procaz e irresistible de la carne y el deseo donde se manifiesta 
en plenitud el Espíritu Santo. Todos ellos conforman la imagen blasfema de la Divinidad Invisible.

La noción de "Divinidad Invisible" devalúa a la figura del "voyeur". Ciertamente, esta figura es importante en varias obras de García Ponce ("El gato", De anima), como ya lo ha señalado con insistencia un sector de la crítica. Pero en el caso del cuento "Rito", lo importante no es el acto de la contemplación, propio del "voyeur". Lo fundamental consiste en la necesidad de "entregar" a la propia esposa a todos. Como dice Pierre Klossowski, la máxima aspiración consiste en "compartir un bien tanto más inmutable cuanto que permanece incomprensible" (La revocación, 50). Aquí, la acción de "prestar" es definitiva: el marido "presta" a su esposa, y el desconocido se "presta" a una situación inconcebible. Es en el rito, en el culto, donde la "costumbre" llamada "las leyes de la hospitalidad" consiste en la entrega de la esposa por el esposo a todos los huéspedes" (García Ponce, La errancia, 55). Un "voyeur" solamente contempla una acción que satisface su morbo y su perversión inmediatos. Por lo mismo, es incapaz de "ver" a la "Divinidad Invisible". El perverso esposo que "presta" a su esposa a un desconocido aspira a que su acción (la de "prestar", no la de "ver") le permita contemplar lo Invisible, lo Inconcebible. El individuo que cumple con las leyes perversas de la hospitalidad es mucho más que un simple y vulgar "voyeur". Desde este punto de vista, en el espectáculo sagrado del cumplimiento de las leyes de la hospitalidad la figura del voyeur no es más que una triste referencia. Lo fundamental tiene que ver con los misteriosos recursos de las leyes de la hospitalidad que parten de lo humano para elevarse a lo divino por medio de la perversión (en el sentido de la perversidad) del principio teológico de la identidad de los seres. En el cumplimiento de dichas leyes se revela que los caminos del Señor son en verdad inescrutables y que, como decía el poeta Gilberto Owen, "Por la carne también se llega al cielo" (Obras, 103); o al menos eso se intenta.

No obstante, la perversidad como experiencia de lo divino en el ámbito del mal está corroída por la ironía. Su símbolo está constituido por la contradicción y la imposibilidad. Como en una pintura, es un instante eterno pero que al mismo tiempo transcurre al estar en la vida. Inmóvil y en movimiento, pleno de contradicciones que se sufren y se gozan al 
mismo tiempo. Como ironía romántica, el acceso a lo absoluto eterno de la experiencia mística es una aspiración inevitable pero imposible de lograr del todo. Sin embargo, es una decepción enriquecedora, pues en relación con el arte da lugar a la creación de importantes obras de literatura. Como en el caso de Borges, Musil y Klossowski - escribe García Ponce-, el instante eterno, finalmente, es ilusorio, pues la búsqueda de la verdadera identidad o de la eternidad es sólo una "fatigada esperanza" de lograr lo absoluto de la eternidad. Es, también, una ilusión del falso Dios del que hablaban los gnósticos: "el demiurgo menor que se sabe destinado a proponer absolutos que no lo son en verdad sino que afirman la imposibilidad del absoluto haciéndolo posible en su misma negación. Es siempre el mismo camino: se trata de saber que 'lo imposible es"” (García Ponce, La errancia, 85).

\section{REFERENCIAS}

Blanchot, Maurice, Lautréamont y Sade, México, Fondo de Cultura Económica, 1990.

CRUZ, san Juan de la, Obras completas, edición crítica de Lucinio Ruano de la Iglesia, Madrid, Biblioteca de Autores Cristianos, 2012.

GarCía Ponce, Juan, La errancia sin fin: Musil, Borges y Klossowski, Barcelona, Anagrama, 1981.

García Ponce, Juan, "Thomas Mann y lo prohibido", en Apariciones. Antología de ensayos, México, Fondo de Cultura Económica, 1987, 247-261.

García Ponce, Juan, Una lectura pseudognóstica de la pintura de Balthus, México, Ediciones del Equilibrista, 1987.

García Ponce, Juan, "Algunos apuntes sobre la costumbre conocida como libertinaje", Moralistas y libertinos, Biblioteca de México, números 59 y 60, México, Consejo Nacional para la Cultura y las Artes, 2000, 2-7.

García Ponce, Juan, Teología y pornografia. Pierre Klossowski en su obra: una descripción, México, Era, 2001.

García Ponce, Juan, "Rito", en Obras reunidas I. Cuentos, México, Fondo de Cultura Económica, 2003, 264-288.

Jonas, Hans, La religión gnóstica. El mensaje del Dios Extraño y los comienzos del cristianismo, Madrid, Siruela, 2003.

KLossowski, Pierre, La revocación del Edicto de Nantes, Barcelona, Tusquets, 1998.

KLossowski, Pierre, Roberte, esta noche, Barcelona, Tusquets, 1997. 
LeCumberri Cilveti, Ángel, Introducción a la mística española, Madrid, Cátedra, 1974.

Lowry, Malcolm, El volcán, el mezcal, los comisarios, México, Universidad Veracruzana, 2008.

Owen, Gilberto, Obras, México, Fondo de Cultura Económica, 1996.

PoE, Edgar Allan, "El demonio de la perversidad", en Cuentos completos, edición comentada, Madrid, Páginas de Espuma, 2008, 191-196.

Rosado Z., Juan Antonio, "Erotismo y misticismo en Juan García Ponce. Una lectura de la novela De anima", en Juan García Ponce y la Generación de Medio Siglo, México, Universidad Veracruzana, 1998, 111-120.

Teresa de Jesús, santa, Obras completas, Salamanca, Sígueme, 1997. 